\title{
EDUCAÇÃO NO CAMPO E TRABALHO: UM ESTUDO DAS ESCOLAS MUNICIPAIS RURAIS DE UBERLÂNDIA-MG
}

Ana Cecília Oliveira Silva ${ }^{1}$

Fabiane Santana Previtali ${ }^{2}$

\section{RESUMO}

O objetivo deste trabalho é discutir o projeto educacional das escolas municipais rurais de Uberlândia/MG a fim de verificar em que medida o projeto adéqua-se às especificidades de estudantes no campo tal como dispõe a LDB 9.394/96. A metodologia implicou em ampla revisão bibliográfica e documental sobre o tema e pesquisa de campo com aplicação entrevistas semi-estruturadas às diretoras e à coordenação pedagógica das escolas. $\mathrm{O}$ trabalho de campo foi realizado no primeiro semestre de 2009 em 5 escolas selecionadas segundo critérios de localização e características da comunidade no entorno da escola. Constatou-se que o modelo de gestão, os conteúdos, os projetos e a formação de professores de tais escolas seguem a mesma lógica das escolas urbanas, confirmando a tese neoliberal vigente de que modernização é sinônimo de urbanização da sociedade. Tem-se então a mera adaptação do serviço educacional oferecido na cidade para o campo, subjugando a população camponesa a este modelo que desconsidera a sua cultura e está dissociado de suas vivências. Concluiu-se que o ensino oferecido nas escolas do campo reproduz os valores hegemônicos da sociedade capitalista burguesa de forma ainda mais precarizada que na cidade.

Palavras-chave: Educação no Campo; Trabalho; Movimentos Sociais no Campo.

\section{FIELD EDUCATION AND LABOR: A STUDY OF RURAL SCHOOLS OF UBERLÂNDIA-MG}

\begin{abstract}
The purpose of this paper is to discuss the educational project of the rural schools of Uberlândia/MG and to see how the project meets the specific needs of students in the field as presents in the LDB-9.394/96. The methodology included extensive literature review and research in papers about the subject and field research with application of questionnaires with semi-structured interviews to schoolmaster and school's pedagogical coordination. The fieldwork was conducted in the first half of 2009 in five Rural Municipality School selected according to criteria of location and characteristics of the community surrounding the school. It was noted that the management model, the content, the projects and the training of teachers from rural schools follow the same logic of urban schools, confirming the current neo-liberal thesis that modernization is synonymous of urbanization of society. See the mere adaptation of educational service offered in the city to the countryside, subjecting the peasant population to this template which disregards their culture and is decoupled from their experiences.
\end{abstract}

Keywords: Field Education; Labor; Social Movements in the Countryside. 


\section{APRESENTAÇÃO}

Este trabalho é resultado de uma pesquisa de mestrado desenvolvida no Programa de Pós-Graduação da Faculdade de Educação da Universidade Federal de Uberlândia no período de Março de 2009 à Março de 2011, na linha de pesquisa Políticas e Gestão em Educação que teve como objetivo principal investigar o projeto educacional das escolas municipais rurais de Uberlândia-MG. Participaram da pesquisa diretores de 5 escolas, assim como a coordenação pedagógica da secretaria municipal de educação. Como instrumentos de construção dos dados foram utilizadas entrevistas semi-estruturadas e pesquisas nos projetos político-pedagógicos das respectivas escolas. A investigação obteve auxílio financeiro da Capes durante 7 meses.

Ao longo do estudo sobre o projeto educacional desenvolvido nas escolas, dentre outros aspectos, questionamos a relação entre os projetos político-pedagógicos, currículos, ou projetos de formação de professores desenvolvidos nas escolas e possíveis especificidades da zona rural. Buscamos relacionar também o ensino oferecido nestas escolas com a problemática da formação para o trabalho, especificamente ao trabalho no campo, investigando sobre a perspectiva de futuro destes alunos, se no campo ou na cidade.

A análise desenvolvida e a construção dos dados foram baseados na concepção materialista histórica dialética, desenvolvida inicialmente por Karl Marx, intelectual e revolucionário alemão do final do século XIX. Segundo este referencial teóricometodológico, a realidade é uma síntese de múltiplas determinações, as quais são, por sua vez, dadas historicamente no desenvolvimento das relações de produção. Relações de produção são as formas como os homens se organizam para transformar a natureza e garantir a reprodução da vida.

Portanto, para compreender a relação entre as escolas municipais rurais de Uberlândia-MG e o ideal político e econômico do município, investigamos o histórico do desenvolvimento econômico do país e o ideal de educação que foi sendo edificado ao longo do desenvolvimento da sociedade de classes capitalista. Transitamos por elementos macro-sociais, relacionados à economia mundial e nacional, e micro-sociais, que são aspectos intrínsecos ao contexto investigado. Juntas, as condições micro e macro-sociais determinam as relações sociais, políticas e econômicas que se dão no meio rural e influenciam as políticas públicas para a educação no campo no Brasil e especificamente no município de Uberlândia-MG.

Inicialmente apresentaremos a discussão teórica sobre Educação, Trabalho e Reestruturação Produtiva do Capital, da forma como a compreende o referencial teórico do materialismo histórico-dialético. Perfazendo uma análise histórica da educação, compreendida desde a sua forma mais primitiva, na qual cada geração passava seus ensinamentos à seguinte através do trabalho, atividade cotidiana que garantia o sustento do grupo, e caminhando na história para compreender o papel que a instituição escolar assume na sociedade moderna. Buscamos demonstrar como a institucionalização da educação está relacionada à manutenção da hegemonia do capital.

Em seguida situamos o projeto educacional desenvolvido nas escolas municipais rurais de Uberlândia no contexto do desenvolvimento das forças produtivas deste município, que reúne grandes empresas relacionadas à agricultura de mercado, o que influencia diretamente na desvalorização do modo de reprodução da vida no campo. Este projeto de educação do campo adaptado da cidade, voltado indiretamente para a sustentação do modelo agroexportador é, todavia, perpassado pela resistência de professores que não se adaptam à estrutura preestabelecida, e no cotidiano da docência 
apresentam propostas educacionais significativas para a população camponesa. Como forma de resistência a este modelo hegemônico de educação, existe ainda a perspectiva educacional contestatória apresentada pelos movimentos sociais de luta pela terra, que contrapõe à educação formal disponibilizada pelo Estado, baseada na indissociabilidade entre educação e trabalho, e engajada num projeto de transformação da realidade camponesa.

\section{EDUCAÇÃO, TRABALHO E REESTRUTURAÇÃO PRODUTIVA}

Os estudos que relacionam Trabalho e Educação constituem uma área de pesquisa em educação com destacada relevância, tanto no meio acadêmico quanto nas propostas educacionais dos movimentos sociais contestatórios à ordem do capital. A Associação Nacional de Pós-Graduação e Pesquisa em Educação - ANPEd possui um GT Trabalho e Educação que agrupa diversos pesquisadores com esta temática central, mas com enfoques diversos nas "relações que se estabelecem entre o mundo do trabalho e a educação, nelas cabendo formação profissional, formação sindical, reestruturação produtiva, organização e gestão do trabalho, trabalho e escolaridade, subjetividade e trabalho etc." (CIAVATTA; TREIN, 2003, p. 140). São preocupações centrais deste GT, desde a sua criação:

Entender o mundo do trabalho como processo educativo, vale dizer, compreender a pedagogia que se desenvolve nas relações sociais e produtivas no modo de produção capitalista e identificar os espaços de contradição que engendram a construção de uma nova pedagogia comprometida com os interesses da classe trabalhadora (CIAVATTA; TREIN, 2003, p. 143-144).

Há neste comprometimento uma análise teórico-metodológica específica baseada no materialismo histórico-dialético. Tal referencial considera o trabalho como principal atividade humana, sendo que é nesta relação entre o homem e a natureza que são satisfeitas as necessidades básicas de sobrevivência. Assim, à medida que o homem transforma a matéria (natureza), segundo a sua intenção, ele modifica a si mesmo física e espiritualmente. "Atuando assim sobre a natureza externa e modificando-a, ao mesmo tempo modifica a sua própria natureza". (MARX, 1980, p. 202).

Partindo da concepção dialética de história, compreendemos a escola dentro dos condicionantes sociais no qual ela se insere, sendo que a instituição escolar faz parte da manutenção e da transformação ideológica da sociedade. É uma das Superestruturas ${ }^{3}$ que mantém as relações sociais de produção. Por isso a importância de relacionarmos as práticas pedagógicas e a organização escolar à Infra-estrutura social, que são as Relações de Produção e as Forças Produtivas, que dão sustentação e são o motivo de ser das instituições educacionais predominantemente capitalistas.

Tendo como referência a centralidade do trabalho na constituição da humanidade, compreendemos a educação como o ato da sociedade transferir às novas gerações os conhecimentos desenvolvidos historicamente e que permitiram a perpetuação da espécie humana. Juntamente com o ensino de técnicas de transformação da natureza (o trabalho em si), os seres humanos transmitem entre si aspectos culturais ligados à sociabilidade, como uma via de mão dupla. Esta educação está ligada à reprodução de valores e costumes, assim como à transformação destes ao longo da história.

Nas comunidades primitivas, em que prevalecia o modo de produção comunal, a educação estava intimamente relacionada às atividades cotidianas. Não havia separação em classes sociais e o trabalho coletivo garantia a sustentação de todos. Os valores da 
coletividade eram transmitidos entre as gerações, não havendo uma instituição educacional com este fim específico, como são as escolas.

A escola tem sua origem com o advento da propriedade privada de terras na sociedade grega e romana da Antiguidade. Com a posse da terra na mão de uma só pessoa, a regra da produção em coletividade é substituída pela separação em classes sociais, entre os proprietários e os não proprietários dos meios de produção. A "educação espontânea da sociedade mediante a qual as novas gerações se assemelham às mais velhas era adequado para a comunidade primitiva, mas deixou de sê-lo à medida que esta foi lentamente se transformando numa sociedade dividida em classes". (PONCE, 2007, p.22). A instituição escolar se encarregou então, da formação daquela fração da sociedade que vivia da exploração do trabalho dos outros se beneficiando desta condição e criando a sua própria cultura e valores, transmitidos na escola através da formação intelectual e moral. Com disposição total para tanto, já que não tinham que trabalhar para satisfazer suas necessidades, desenvolvem a "escola", que em grego significa o lugar do ócio. (SAVIANI, 2002, p.152). A educação das massas se restringia à educação religiosa, que era importante para manter o estado de dominação. Por outro lado, a educação para a prática do trabalho continuava acontecendo no cotidiano do desenvolvimento das funções dos servos.

No feudalismo as trocas serviam de apoio às atividades do feudo, suprindo-o com mercadorias que não eram produzidas no campo. O enriquecimento dos nobres senhores feudais e o uso da moeda nas transações comerciais favoreceram o crescimento das atividades mercantis. Estavam instaladas, portanto, as condições para ascensão das populações das cidades (os burgueses), que eram aqueles que viviam do trabalho nos mercados e da produção artesanal, transformando manualmente os produtos do campo. Aos poucos os burgueses foram tomando consciência de sua condição de classe, sendo fortalecidos pelas medidas que retiravam das monarquias o poder total sobre o território e sobre os servos (PONCE, 2007, p.98). As condições favoráveis para que o centro da produção se deslocasse do campo para a cidade se deram primeiramente na Inglaterra no século XVIII. Este processo influenciou outras revoluções burguesas na Europa a partir do século XIX, ficando conhecido como a I Revolução Industrial. A acumulação primitiva de capitais através do comércio inaugurou novas formas de produção coletiva com predominância da compra e venda da força de trabalho, caracterização básica do modo de produção capitalista.

A doutrina liberal constituiu a base de sustentação moral deste modo de produção que veio organizar e controlar as relações humanas numa tendência crescente e global como nunca visto antes. Segundo o liberalismo o indivíduo é considerado livre para vender a sua força de trabalho, que é a única coisa que ele possui de fato, já que a propriedade privada dos meios de produção se expande da propriedade da terra - como principal meio de produção até então - para todas as ferramentas e todo o processo de trabalho. O direito positivo, através dos contratos sociais e das Constituições foi determinante para o desenvolvimento do liberalismo, com a subordinação das vontades individuais à ordem necessária ao crescimento do mercado. Os filósofos contratualistas Tomas Hobbes (15881679), John Locke (1632-1704), Jean-Jacques Rousseau (1712-1778), são precursores da teoria liberal que influenciaram as transformações ocorridas desde o século XVIII.

Neste contexto a escola passou a ser uma instituição fundamental para o processo de desenvolvimento econômico, sendo responsável pela formação cultural, técnica e intelectual que edificou a sociedade de classes, através da formação de trabalhadores para atender aos diversos postos do mercado de trabalho (SAVIANI, 2002). O direito universal à escola foi uma bandeira da burguesia em ascensão. Desde então a escola se constituiu como o espaço dominante de educação da população, sendo superior a qualquer outra 
forma não escolar de ensino como a educação não escolar, educação não-formal ou informal. Vale dizer que quando dizemos de uma "educação para todos", não estamos tratando de uma forma homogênea de educação, uma vez que a divisão social do trabalho no capitalismo implica sempre num corte de classe na qualidade e no tipo de educação oferecido. Se por um lado há uma tendência de ampliar o acesso dos trabalhadores à leitura, escrita e contagem, conhecimentos básicos para a vida na sociedade moderna, a burguesia tem acesso diferenciado a uma gama de conhecimentos produzidos historicamente que ficam de fora da formação de massa, tecnicista, a que têm acesso os trabalhadores.

A centralidade da escola como superestrutura constituinte do modo de produção pode ser compreendida quando examinamos as relações de trabalho capitalistas em que os trabalhadores, donos unicamente de sua força de trabalho, são responsáveis pela execução e estão sob controle dos proprietários dos meios de produção, responsáveis pelo trabalho intelectual. Temos então que o conhecimento agrega valor à mercadoria, ao mesmo tempo em que se torna mercadoria. $\mathrm{O}$ conhecimento é expropriado do trabalhador, aprimorado pela ciência que o particiona e retorna ao trabalhador na forma de técnicas. $\mathrm{O}$ trabalhador passa a vender a sua força de trabalho, em troca de um salário, enquanto o patrão controla a execução do serviço e só disponibiliza as informações específicas necessárias à execução das tarefas (BRAVERMAN, 1977). A frase atribuída a Adam Smith "Instruções aos trabalhadores, porém em doses homeopáticas", esboça a necessidade capitalista de formar os trabalhadores, porém, no limite dos conhecimentos necessários para a execução de suas funções.

Importante marco que deu sustentação a este modelo dualista de formação para o mercado de trabalho foi a Teoria do Capital Humano, desenvolvida por Theodoro Schultz no final dos anos 1950 e início de 1960 para explicar as diferenças de desenvolvimento econômico e social das nações, e as desigualdades entre grupos sociais e indivíduos. Tal teoria foi utilizada no desenvolvimento do modelo tecnicista e economicista de formação do trabalhador, aplicado à educação em geral através dos projetos dos organismos internacionais como o Banco Mundial e demais aparelhos de hegemonia do capital. (KUENZER, 1987; FRIGOTTO, 1998). No Brasil as reformas educacionais do período da ditadura militar estruturaram o sistema de ensino dentro destes parâmetros, visando à qualificação técnica da força de trabalho necessária para o desenvolvimento industrial empreendido pelo governo.

Gentili (2002) apresenta a desintegração da promessa integradora da educação a partir da crise capitalista de 1970, criticando o papel assumido pelo Estado. Se antes ele atuava como principal promovedor do direito à educação e do direito ao trabalho, passa a ocupar um papel secundário, garantindo a privatização da educação escolar. A Teoria do Capital Humano entra em decadência porque fica explícita a incapacidade da escolarização promover diretamente o desenvolvimento econômico equânime. O Brasil, por exemplo, caminhou para a universalização da oferta da educação básica, foi uma das nações de elevado índice de crescimento econômico no final do século XX e, no entanto, a desigualdade social e a condição de miséria de grande parte da população não se alteraram.

O capitalismo passou por uma crise estrutural no final dos anos 1960 e início dos anos 1970 que foi decorrência de causas complexas, uma vez que o momento era de "mutações intensas, econômicas, sociais, políticas, ideológicas com fortes repercussões no ideário, na subjetividade e nos valores constitutivos da classe-que-vive-do-trabalho" (ANTUNES, 1999, p.35). Esta crise levou um processo de reestruturação produtiva do capital que foi influenciado pelo ideário político neoliberal visando garantir a perpetuação da acumulação capitalista. Foi um momento de reestruturar o padrão produtivo organizado 
sobre o binômio taylorismo e fordismo, que já se mostrava desgastado, e elaborar novos padrões de acumulação.

Se no campo da produção o neoliberalismo preconizava a adoção de políticas de reestruturação produtiva, nas relações políticas exigia uma nova postura do Estado na condução da economia. O Estado neoliberal tem como princípio reinante o controle da economia para que tudo transcorra bem nas relações comerciais, por isso é um Estado forte. Mas por outro lado os gastos com o bem estar social devem ser minimizados drasticamente, portanto é um Estado mínimo de garantia de direitos. Em oposição ao modelo de Estado provedor do Walfare State, considerado pelo neoliberalismo como oneroso demais, temos expansão dos princípios de mercado capitalista em esferas que antes eram consideradas "públicas", como saúde, educação, lazer, etc. Estes setores passam a ser gerenciados segundo critérios de lucratividade, configurando na crescente perda de direitos dos trabalhadores.

O cenário indica para o fim das habilidades intelectuais específicas, que dá lugar à generalização de conhecimentos básicos dentro das empresas. Na educação este modelo significa uma suposta necessidade de formação que desenvolva no trabalhador as habilidades básicas no plano do conhecimento, das atitudes e dos valores, produzindo competências para a gestão da qualidade, para a produtividade e competitividade e, conseqüentemente, para a "empregabilidade". "Empregabilidade não significa, então, para o discurso dominante, garantia de integração, senão melhores condições de competição para sobreviver na luta pelos poucos empregos disponíveis: alguns sobreviverão, outros não." (GENTILI, 2002, p. 54).

Diante da necessidade em demonstrar o desenvolvimento da educação brasileira para atender à demanda do mercado privilegiam-se os números. E na educação básica a conseqüência disto é que muitos alunos vão sendo aprovados e concluem mal sabendo escrever o próprio nome, e no ensino superior a lógica produtivista não avalia a qualidade dos trabalhos desenvolvidos, e sim o número de publicações. A Pesquisa Nacional por Amostra de Domicílios - PNAD - 2009 demonstrou que um em cada cinco brasileiros (20,3\%) é analfabeto funcional. Com relação à ampliação do acesso ao ensino superior, questiona-se a parcela de pessoas que conseguem concluí-lo, e principalmente a baixa qualidade da formação oferecida. (BEZERRA NETO; BEZERRA, 2008). A meta de expansão das ofertas do ensino superior do Plano Nacional de Educação (PNE - Lei $n^{\circ}$ 10.172/2001) era de aumentar a proporção de jovens de 18 a 24 anos matriculados em curso superior de $9 \%$ para $30 \%$ até 2010 . No entanto esta meta está sendo alcançada através do Programa Universidade para Todos - PROUNI - que privilegia a concessão de benefícios, pela expansão da oferta no setor privado, e não de direitos. (CATANI; HEY; GILIOLI, 2006).

O discurso neoliberal afirma que atualmente, inclusive nos países mais pobres, não faltam escolas, faltam boas escolas; não faltam professores, faltam professores mais qualificados; não faltam recursos para financiar as políticas educacionais, ao contrário, falta uma melhor distribuição dos recursos existentes. Nas proposições neoliberais, transformar a escola supõe um enorme desafio gerencial para torná-la mais eficiente. Sendo assim, deve-se reestruturar o sistema para flexibilizar a oferta educacional, promover uma mudança cultural e nas estratégias de gestão, além de transformar o perfil dos professores, reciclando-os. (BEZERRA NETO; BEZERRA, 2008, p.53). 
A individualização da causa do problema do desemprego consiste em culpar o trabalhador que não consegue uma vaga de emprego, ou é demitido, por sua pouca qualificação para o cargo, sendo que, para competir neste mercado, deve comprar um curso de aprimoramento, e adquirir capacidades que lhe dará melhores condições "empregabilidade". Temos então que a culpa do fracasso, ou do sucesso, está no indivíduo e em suas capacidades pessoais, e não na estrutura desigual de oferta de empregos; no desemprego estrutural, que é condição básica de reserva de força de trabalho do sistema capitalista; ou no subemprego e nas contratações temporárias.

\section{UBERLÂNDIA, UMA HISTÓRIA LIGADA AO LATIFÚNDIO E À AGRICULTURA DE MERCADO}

O município de Uberlândia está localizado na região do Triângulo Mineiro que se situa na parte extremo oeste de Minas Gerais e é considerada a segunda maior cidade do estado e a décima maior cidade não-capital do país em termos populacionais. O bioma predominante na região é o cerrado, de vegetação baixa e pouca fertilidade natural, o que o torna impróprio para a agricultura sem correção necessária de nutrientes e acidez.

A cidade possui o segundo maior PIB do Estado, ficando atrás somente da capital, Belo Horizonte. Considerando as cidades que possuem mais de 500 mil e menos de 1 milhão de habitantes no Brasil, Uberlândia apresentou, em 2006, o $9^{\circ}$ maior PIB, superando em produção de bens e serviços algumas capitais de estados brasileiros. (BARROS, 2010, p.10). Tais dados nos dão um panorama do desenvolvimento da cidade, indicando um município com desenvolvimento econômico e social que podem ser considerados referência nacional de qualidade e de crescimento. No entanto, é importante apontarmos para as limitações desses indicadores em apreender a totalidade da qualidade de vida em um território. Assim, existem contradições sociais do município de Uberlândia que não são explicitadas pelos indicadores estatísticos.

Refletindo as contradições e dificuldades sócio-econômicas da maioria das sociedades brasileiras, segundo estudos realizados no ano de 2001 pelo Instituto de Economia da UFU, a pobreza atinge aproximadamente a $43,30 \%$ da população de Uberlândia, sendo que 10,70\% são considerados indigentes, isto é, vivem com uma renda média de $\mathrm{R}$ \$ 40,48 por mês. Outro aspecto significativo de grande parte da população refere-se ao fato de que $40,15 \%$ possui apenas o Ensino Fundamental incompleto e $10,22 \%$, o Ensino Médio incompleto.

Além desses dados, no campo sócio-econômico, estudo realizado por Gandolfi (2001), constatou que o município apresenta um perfil de emprego similar ao do Brasil, onde impera baixos salários, ampla difusão do trabalho informal, baixa presença dos jovens no mercado de trabalho, assim como predominância do gênero masculino, principalmente na Indústria de Transformação e Comércio. Uberlândia também apresentou piores condições de geração de trabalho quando comparado com os indicadores macroeconômicos de outras regiões semelhantes a esse município, principalmente onde há um predomínio de tempo de serviço e escolaridade baixa entre os trabalhadores empregados formalmente.

Uberlândia localiza-se na malha rodoviária de importante ligação entre o centro político do país (Brasília) e o econômico (São Paulo). Com isso, a cidade conquistou uma política industrial mais ousada e a constituição de outras estratégias de desenvolvimento urbano, fundamentalmente a partir da década de 70, que a levariam para um nível de crescimento bastante superior ao de outras cidades da região. Pois, a partir dessas ações, 
desencadeou-se um dinâmico processo de estruturação de uma cidade complexa, amparada não só pela força agroindustrial, mas também pelas intensivas necessidades de um setor de serviços que retroalimentou o crescimento urbano.

Assim, se desenvolve na cidade um setor de serviços que sobrepõe aos demais setores. Temos que o setor de agropecuária ocupa apenas 2,46\% do total do PIB do município, enquanto e o setor de indústria ocupa $27,61 \%$ e o de serviços $69,93 \%$. (BARROS, 2010). No entanto, diversas empresas em Uberlândia não são categorizadas no setor de "agropecuária", mas estão de alguma forma, relacionadas a este setor.

Outro indicativo da relevância das empresas agrícolas e de outras relacionadas a este setor é a participação destas nas exportações do município. Dentre as principais empresas exportadoras do município estão: Souza Cruz, empresa do ramo de fumo e cigarros; a Granja Planalto, do ramo de alimentos; Resinas Tropicais, empresa de extração de resina natural de Pinus; Monsanto do Brasil, ADM do Brasil, AWB Brasil, Multigrain, Cargill, ABC-INCO, todas são empresas de produtos para a agricultura - alimentos, sementes transgênicas, fertilizantes, agrocombustíveis e produtos químicos; Cooperativas de agricultores; e Bertin S.A. empresa de proteína animal. (BARROS, 2010).

Em contraposição às grandes empresas agroindustriais, com investimento tecnológico "de ponta" existe uma agricultura familiar precária e intensos conflitos pela posse da terra. A reestruturação produtiva no campo, com a exigência de aquisição de máquinas, sementes melhoradas, adubos, agrotóxicos, acirraram a condição de subordinação dos pequenos produtores, dependentes das linhas de crédito, dos atravessadores, das indústrias. Assim, o investimento público através de linhas de crédito e incentivos fiscais dá mais sustentação às empresas privadas agroindustriais do que aos produtores da agricultura familiar.

Existe uma grande quantidade de conflitos por terra em toda a extensão do Triângulo Mineiro. De todas as áreas rurais ocupadas por organizações de trabalhadores no estado de Minas Gerais, registradas pelo INCRA-MG durante os anos de 1999 e 2001, que somam 162 ocupações, 113 ocorreram no Triângulo Mineiro e Alto Paranaíba. Gomes (2004) demonstrou em sua dissertação de mestrado como a ofensiva do capital é acompanhada por uma organização dos trabalhadores rurais nos movimentos de luta pela terra, que defendem a necessidade da Reforma Agrária para eliminar as desigualdades sociais do campo.

Os movimentos dos Sem Terra do município de Uberlândia nos interessam nesta investigação por comporem uma parcela considerável dos alunos que estudam nas escolas municipais rurais, e ainda por representarem uma proposta educacional que se contrapõe ao modelo neoliberal de escola.

Podemos perceber, através deste panorama da composição econômica e social do meio rural uberlandense que há um projeto de crescimento econômico em desenvolvimento no município que privilegia o setor de serviços e a urbanização. Portanto, buscamos em nosso trabalho de campo, investigar: como a escola do meio rural, direcionada para a população trabalhadora que reside no campo, reflete e corrobora esta concepção agroindustrial e o ideal de desenvolvimento sustentado politicamente em Uberlândia?

\section{AS ESCOLAS MUNICIPAIS RURAIS DE UBERLÂNDIA-MG}

A rede municipal de ensino fundamental de Uberlândia possui 37 escolas urbanas, mais as 13 escolas localizadas na zona rural. Possui ainda as escolas municipais de educação infantil e um centro de estudos - Centro Municipal de Estudos e Projetos 
Educacionais Julieta Diniz - CEMEPE, que realiza a capacitação dos professores de toda a rede.

Das 13 escolas municipais rurais, que compõem a rede de ensino fundamental da Secretaria Municipal de Educação, 4 estão localizadas em distritos, 3 em comunidades e bairros periféricos e 6 estão em fazendas da zona rural um pouco mais distantes da cidade. São oferecidos nestas escolas: o ensino fundamental completo, do $1^{\circ}$ ao $9^{\circ}$ ano, e em algumas delas o curso de Educação de Jovens e Adultos - EJA, no período noturno e salas do último ano da educação infantil. Não há na Secretaria um órgão específico destinado a organizar as demandas das escolas rurais, elas estão organizadas dentro do quadro geral das escolas fundamentais do município.

As crianças do ensino infantil que residem na zona rural do município não têm acesso a nenhuma instituição oficial de educação na zona rural, fora algumas escolas que têm salas do último ano desta modalidade de ensino. Já os alunos do ensino médio contam com transporte escolar municipal que faz o deslocamento de suas residências até as escolas da cidade.

Levando em conta estes critérios e de acordo com a disponibilidade manifestada por cada diretor das escolas para participar do trabalho, fizeram parte desta pesquisa: a escola Leandro José de Oliveira, por ser a mais distante do centro urbano e abranger uma área com vários acampamentos e assentamentos de reforma agrária; a escola do Moreno, por sua proximidade com o centro urbano e por ter clientela composta basicamente por trabalhadores rurais assalariados e sitiantes; a escola Dom Bosco, também próxima à zona urbana, e localizada numa área de conflitos por terra; a escola José Marra da Fonseca, localizada num distrito do município de Uberlândia, o de Cruzeiro dos Peixotos; e a escola de Sobradinho, localizada dentro do Instituto Federal do Triângulo Mineiro, atendendo alunos filhos de funcionários, de trabalhadores rurais assalariados e moradores de chácaras da região.

Para manter sigilo nos dados da pesquisa foram atribuídos codinomes, que simbolicamente remetem às espécies de flores do cerrado, a cada um dos entrevistados.

\section{AS PARTICULARIDADES DA POPULAÇÃO CAMPONESA EM QUESTÃO}

Buscamos em nossa entrevista, compreender a representação dos sujeitos entrevistados sobre os alunos do campo, comparando-os com os da cidade. Se há uma concepção de que a extinção do camponês, de sua cultura e forma de trabalho tradicional, é uma prerrogativa da expansão do capitalismo, perguntamo-nos: o que permanece de particular na organização do campo, que se manifesta na escola rural e a torna dotada de condições específicas de trabalho pedagógico?

Alguns dos entrevistados apontaram que os alunos da zona rural têm acesso a um universo cultural distinto daquele da cidade, levando a um processo de aprendizagem também diferenciado. No trecho abaixo podemos perceber como, por vezes, em comparação com a vida na cidade, a vida na roça é considerada inferior, com menos possibilidades de acesso a informações.

No português eles deixam a desejar porque o vocabulário deles é muito restrito, aqui na zona rural o recurso visual, porque na cidade eles passam por uma placa, lê, aqui é mais difícil. (Acácia)

Percebemos aqui que o padrão, a referência do adequado, é o urbano, o vocabulário, as informações, que fazem sentido segundo um currículo geral, é determinado de forma arbitrária para a população do campo. Contudo, podemos perceber que os 
professores reconhecem este universo cultural diferenciado, e se preocupam em modificar a metodologia de ensino, acreditando, sobretudo, na capacidade de aprendizagem desses alunos.

Mas eu sempre trato meus alunos assim, porque eu descobri que eles não eram iguais, mas foi uma descoberta mesmo, porque no inicio eu também achava que eles eram iguais, depois eu fui descobrindo, vendo as dificuldades, e fui descobrindo que não era, aí eu tive que mudar minha metodologia. (Dália)

Outra particularidade dos alunos do campo que pôde ser identificada na fala dos diretores foi o bom comportamento, a docilidade e receptividade que estes alunos têm com relação à escola, fato que atribuíram a causas diversas, como a relação do aluno com a família, da escola com a comunidade, e o número de alunos por sala.

Pode ser percebida nos seguintes trechos uma referência à família camponesa como um núcleo mais estruturado, que dá melhor condições de educar os filhos, o que porventura pode estar relacionado à menor influência de fatores externos (muitos vizinhos, violência, televisão, excesso de informações, etc.) nesta educação:

Os alunos de zona rural, eles são mais assim, você cativa melhor, o contato com os pais e maior, mesmo que esses pais sejam analfabetos, mas todo dia, toda hora, eles tão presentes ali, eles às vezes moram em zona rural, e não trabalham fora, e mesmo que trabalhem, eles tão trabalhando ali perto de casa, no quintal da casa, então eles têm um contato familiar muito maior do que os meninos de zona urbana, então a disciplina em sala de aula às vezes é melhor do que o na zona urbana. (Dália)

O fato das crianças serem mais amáveis, melhores de lidar do que as crianças da cidade também foi relacionado ao menor índice de violência na escola do campo, se comparado com as escolas das periferias da cidade. Alguns diretores afirmaram que na realidade em que atuam a quantidade de alunos por sala de aula é menor do que na cidade, contribuindo para o trabalho do professor, que pode guiar melhor os alunos.

Embora alguns diretores tenham apontado para diferenças entre os alunos da zona rural e urbana, em certos momentos eles se contradizem afirmando que as diferenças entre o campo e cidade não existem mais.

Principalmente na época que eu entrei, a zona rural ela tinha uma especificidade, hoje ela já não tem tanto mais, como você vai poder constatar na sua pesquisa. Porque a maioria não tinha nem energia elétrica, não tinha acesso à televisão, então eram crianças que tinham uma dinâmica e uma rotina totalmente diferente dos alunos da zona urbana. (Rosa)

Identificamos aí a contradição da construção da cultura hegemônica capitalista, que embora seja esta uma tendência, a de homogeneização de valores culturais, típicos da modernidade, há sempre uma resistência por parte dos trabalhadores que faz com que algumas características da cultura camponesa permaneçam. 


\section{PROJETO POLÍTICO-PEDAGÓgICO, CURRÍCULO E FORMAÇÃo DE PROFESSORES DO CAMPO}

Os movimentos em defesa de uma educação do campo debatem constantemente a necessidade de uma formação específica para o educador do campo. Dentre as experiências mais relevantes estão os cursos de formação superior em 'Licenciatura do campo', desenvolvidos pelo MST em parceria com instituições federais de ensino superior. As "Diretrizes Operacionais para a Educação Básica nas Escolas do Campo- DOEBEC" (Parecer $n^{0}$ 36/2001 e Resolução1/2002 do CNE) prevêem com relação à formação do educador do campo que

Art. 12:

Paragrafo único: Os sistemas de ensino, de acordo com o artigo 67 da LDB desenvolverão políticas de formação inicial e continuada, habilitando todos os professores leigos e promovendo o aperfeiçoamento permanente dos docentes.

Art. 13: Os sistemas de ensino, além dos princípios e diretrizes que orientam a Educação Básica no país, observarão, no processo de normatização complementar da formação de professores para o exercício da docência nas escolas do campo, os seguintes componentes:

I - estudos a respeito da diversidade e o efetivo protagonismo das crianças, dos jovens e dos adultos do campo na construção da qualidade social da vida individual e coletiva, da região, do país e do mundo;

II - propostas pedagógicas que valorizem, na organização do ensino, a diversidade cultural e os processos de interação e transformação do campo, a gestão democrática, o acesso ao avanço científico e tecnológico e respectivas contribuições para a melhoria das condições de vida e a fidelidade aos princípios éticos que norteiam a convivência solidária e colaborativa nas sociedades democráticas.

A formação específica para a atuação no campo foi um tema discutido em nossas entrevistas com as diretoras, que manifestaram a necessidade desta formação, o que já foi apresentado como demanda para a prefeitura em diversas ocasiões. Quando conversamos com as diretoras das escolas e com a própria Secretaria de Educação é unânime o reconhecimento da necessidade de uma formação específica dos educadores para atuar neste contexto. Mas, de quem é o papel de oferecer esta formação? Percebemos que a Secretaria de Educação se exime desta tarefa, e que cada professor na escola adéqua a prática à realidade do campo ao seu modo.

Outra questão que perpassa a formação docente no campo é a do desenvolvimento de um projeto institucional adequado, com planejamento pedagógico e curricular direcionado para o trabalho no campo e definidos coletivamente. Segundo as DOEBEC:

O projeto institucional das escolas do campo, expressão do trabalho compartilhado de todos os setores comprometidos com a universalização da educação escolar com qualidade social, constituir-se-á num espaço público de investigação e articulação de experiências e estudos direcionados para o mundo do trabalho, bem como para o desenvolvimento social, economicamente justo e ecologicamente sustentável.

Portanto, de acordo com as diretrizes, o projeto da escola deve estar relacionado ao trabalho do campo e comprometido com o desenvolvimento social e ambiental. A 
investigação sobre os projetos nos mostrou a ausência de construção coletiva de um projeto institucional voltado para o trabalho no campo. Sendo que cada professor adapta segundo a sua condição o conteúdo à realidade dos alunos.

\begin{abstract}
É assim, nos conteúdos os professores procuram partir da realidade do aluno, mas a proposta curricular é a mesma, é a do município. Mas nos planejamentos a gente tenta dar a cara da escola, por mais que às vezes a gente não consiga atender a todas as necessidades, a gente tenta fazer isso no dia-dia, na questão metodológica. Então é muito legal porque tem dia que as pessoas falam assim, eu tava dando uma aula sobre o assunto $\mathrm{X}$ e os meninos me ensinaram tanto... mas porque é o trabalho deles, eles vão contar a experiência deles e o professor vai entrar num papel de dirigir, de estimular, de passar a ampliar esta visão que ele tem no trabalho dele, e se ele não trabalhar, no mundo que ele vive ali, então eu acho que isso é interessante, embora a gente não tenha isso muito definido, muito claro nas propostas, nos planejamentos, mas a gente vê que na pratica já tem se efetivado alguns trabalhos. (Rosa)
\end{abstract}

\title{
A realidade do campo e a condição de permanência dos alunos neste espaço
}

Outra questão que guiou nossa conversa com as diretoras versava sobre a perspectiva de futuro dos alunos, se este se daria no campo ou na cidade. O discurso das professoras nos dá a impressão de que se o processo educacional "der errado", o aluno fica no campo. Mas, quando ele é bem sucedido, quando é possível o aluno prosseguir nos estudos e atingir um nível mais elevado de qualificação, ele vai para a cidade e não retorna para o campo.

Dália, por exemplo, afirma que a maioria dos alunos que fica é porque não querem continuar estudando e sem perspectivas de trabalhos mais lucrativos, continuam no campo.

Hoje a escola não tem mais volta, quem não estuda vai ter maior problema pra frente. Tem uns que falam, 'ah, eu quero ser tratorista'. (Risada) Quer dizer que o pai é tratorista e coisa e tal, 'Então eu quero ser tratorista, tia', eu falo 'é bom ser tratorista, mas tem que estudar também, pra se outra coisa além de ser tratorista'. Tem que ser outra coisa também, não pode ser só tratorista. (Dália)

Podemos perceber nesta fala de Dália o discurso da necessidade de qualificação profissional para inserção no mercado de trabalho. Temos, portanto, por um lado a conformação do papel da escola no fornecimento de força de trabalho especializada, e por outro a contradição de que esta escola não forma a todos, legitimando o desemprego e desigualdade social. A concepção hegemônica é de que todos têm acesso à educação, sendo assim, os que se empenharem nos estudos, alçando níveis maiores de qualificação garantem a sua colocação em bons postos de trabalho. Sabemos, no entanto, que não existem vagas para todos nestes cargos, e que não são dadas as mesmas condições de acesso à educação de qualidade para os alunos das escolas do campo e as da cidade, para aqueles das escolas públicas e para os das privadas.

A constante necessidade da qualificação profissional, com a cisão entre trabalho manual e intelectual cada vez mais marcada, leva a uma desvalorização das atividades tradicionais do campo, caracterizadas pela transmissão de geração a geração das técnicas e valores culturais da agricultura através da experiência no cotidiano. A qualificação do trabalho no campo, com o investimento em alta tecnologia agrícola está relacionada com o investimento em uma economia camponesa direcionada para a cidade, e mais 
especificamente para o comércio globalizado, ficando as pequenas produções e os trabalhadores tradicionais em situações de sobrevivência precárias. Margarida, uma diretora que possui um vínculo com o meio rural, como moradora, fez uma descrição crítica da situação do camponês atual, afirmando que os alunos vão pra cidade porque o trabalho na zona rural, como proprietário, exige muito investimento e que os jovens vão naturalmente para a cidade em busca de trabalho.

Pra você trabalhar na zona rural você tem que ter dinheiro. Fazenda, você não enriquece na fazenda. Tem que investir em tecnologia e pra investir em tecnologia tem que ter dinheiro. Aí eles vão ficando maiores e gritam, eles querem voltar pra cidade porque lá tem mais espaço de trabalho. Porque roça não dá futuro, sabe esse futuro assim de ganhar bem, enriquecer, não. A menos que você tenha condições financeiras pra investir em tecnologia, senão... hoje se você não investir em tecnologia, a zona rural é gasto mesmo. Não é fácil a vida de roça. (Margarida)

Ela demonstrou conhecer as dificuldades enfrentadas pelos pequenos produtores e trabalhadores rurais tendo consciência da insuficiência das políticas estatais direcionadas para esta população. Sem alternativas de sustentação no campo, os alunos migram para a cidade em busca de melhores condições de vida.

\section{CONSIDERAÇÕES FINAIS}

O modelo educacional implementado pela Secretaria Municipal de Educação nestas escolas é idêntico ao que vigora em toda a rede de escolas fundamentais do município. A Prefeitura se exime do papel da realização de uma formação específica para os professores atuarem na zona rural, não há uma elaboração curricular específica, nem um setor destinado à gestão das escolas rurais. Oferecem um modelo genérico de educação dando as mesmas condições de estrutura física, material, profissional, a todas as escolas da rede municipal. Reconhecem a necessidade de se "pensar algo" específico para estas escolas, mas, no entanto, não há nada formal, concreto, neste sentido. A equipe da escola percebe a necessidade desta formação específica, mas não possui recursos para desenvolver uma proposta (curricular, pedagógica) alternativa, que busque reconhecer as especificidades do campo. As organizações dos trabalhadores do campo, as comunidades do entorno, por exemplo, não conseguem se estruturar neste contexto, para ocupar a deficiência de formação e influenciar o Projeto Político Pedagógico da escola.

Diante de tais fatos, podemos afirmar há um projeto educacional em curso nestas escolas rurais que reflete e corrobora a concepção de desenvolvimento econômico direcionada para a expansão do eixo urbano-industrial, visão que é sustentada politicamente no município de Uberlândia-MG. Este ideal de desenvolvimento, por sua vez, está inserido no contexto da reestruturação produtiva do capital, sob a égide do neoliberalismo.

Contudo esta investigação possibilitou conhecer também experiências de professores que, mesmo isolados, resistem ao padrão hegemônico da educação oferecida ao campo, como uma mera adaptação do modelo urbano e desenvolvem em seu trabalho uma perspectiva diferenciada. Manifestam em seu cotidiano de sala de aula a relação do conhecimento com o contexto em que os alunos vivem, cada um a seu modo, de acordo com suas capacidades individuais. Indicamos para uma pesquisa posterior a necessidade de investigação sobre as práticas profissionais destes professores do campo, especificamente 
sobre aquelas práticas que indicam uma contraposição ao modelo de educação generalista e urbano e que busquem desvelar a realidade do campo. Porque compreendemos que esta ação dos professores representa uma escola que não é homogênea, e que, portanto possui práticas que devem ser valorizadas em seu potencial para problematizar, trazer à tona, a realidade do campo e possibilitar aos alunos uma construção de conhecimento reflexiva e integral.

Porque ressaltamos a necessidade da valorização destas experiências contrahegemônicas? Qual é a especificidade deste campo que tratamos nesta investigação e defendemos que deve ser explicitada no projeto escolar? As entrevistas com as diretoras e a presença na escola enquanto pesquisadoras nos possibilitaram levantar pistas sobre a composição desta escola rural que a torna particular, dotada de especificidades. Apontamos para a necessidade do desenvolvimento de pesquisas que aprofundem o debate sobre as condições de vida, de trabalho e no universo cultural dos alunos que freqüentam estas escolas, o que é importante e pode ser realizado numa outra investigação que tenha este como objetivo central. Mas o fato destes alunos despenderem longos períodos de viagem até a escola, de residirem em regiões diversas e também em condições diversas, como as dos trabalhadores de fazendas, assentados ou acampados, faz com que as escolas do campo tenham demandas, não só estruturais, como o transporte, mas também pedagógicas, que são diferentes das demandas das escolas da cidade.

Porém, desmistificar o caráter desta educação formal, generalista, que homogeniza a população, só faz sentido numa perspectiva de superação do modelo de atendimento educacional assistencialista, oferecido pelo governo e direcionado pelo mercado. A proposta crítica a este modelo, de uma educação do campo, desenvolvida nacionalmente por militantes e intelectuais, enfatiza a valorização de cada grupo segundo suas capacidades e habilidades sendo que o papel da educação é resgatar os princípios humanizadores do trabalho, com a formação onilateral do indivíduo. Experiências paralelas à educação formal vêm sendo desenvolvidas pelo Movimento dos Trabalhadores Rurais Sem Terra - MST, que buscam desenvolver práticas de uma educação do campo propriamente dito, em conformidade com o espaço humano-racional que lhe é próprio, a realidade campesina e sua estrutura sócio-cultural.

Por fim, ressaltamos a possibilidade de investigações sobre as escolas municipais rurais de Uberlândia contribuir para a construção de projetos de educação do campo. $\mathrm{O}$ propósito de demonstrar a vinculação entre o projeto oficial atual das escolas rurais e a concepção ideológica de reprodução de valores capitalistas, está em apontar para a superação do abandono que a população rural se encontra, diante da ausência de políticas públicas específicas voltadas para suas necessidades, ou na ausência de implementação destas.

\section{REFERÊNCIAS}

ANTUNES, R. Os Sentidos do Trabalho - Ensaio sobre a afirmação e a negação do trabalho. São Paulo, SP: Boitempo Editorial, 1999.

BARROS, H. Uberlândia: um retrato de seu desenvolvimento. In: Uberlândia: painel de informações municipais - 2009. Elaboração Álvaro Fonseca e Silva Júnior, et al. Uberlândia: UFU, CEPES, 2010. 
BEZERRA NETO, L. \& BEZERRA, M. C. S. A classe Trabalhadora e a Mundialização do saber. In: LUCENA, C. (Org) Trabalho, Precarização e Formação Humana. Campinas, SP: Editora Alinea, 2008.

BRAVERMAN, H. Trabalho e Capital Monopolista. Rio de Janeiro: Zahar. 1977.

BRASIL. Lei de Diretrizes e Bases da Educação Nacional. Ministério da Educação, 1996.

BRASIL. Diretrizes Operacionais para a Educação Básica nas Escolas do Campo DOEBEC". Parecer n ${ }^{0}$ 36/2001 e Resolução1/2002. Conselho Nacional de Educação.

CATANI, A. M.; HEY, A. P. \& GILIOLI, R. S. P. PROUNI: democratização do acesso às Instituições de Ensino Superior? Educar, Curitiba, n. 28, p. 125-140, 2006. Editora UFPR.

CIAVATTA, M. \& TREIN, E. O percurso teórico e empírico do GT Trabalho e Educação: uma análise para debate. Revista Brasileira de Educação, Set/Out/Nov/Dez 2003, N²4, p. $140-164$

FRIGOTTO, G. Educação, crise do trabalho assalariado e do desenvolvimento: teorias em conflito. In: FRIGOTTO, G. (Org.). Educação e crise do trabalho: perspectivas de final de século. Petrópolis, Rj: Vozes, 1998.

GANDOLFI, M. R. C. Uma análise sobre o emprego formal no município de Uberlândia, Minas Gerais, 2001. Dissertação (Mestrado em Desenvolvimento Econômico) - Instituto de Economia, Universidade Federal de Uberlândia, 2001.

GENTILI, P. Três teses sobre a relação entre trabalho e educação em tempos neoliberais. In: LOMBARDI, J. C. L.; SAVIANI, D. \& SANFELICE, J. L. (Orgs.) Capitalismo, Trabalho e Educação. Campinas, SP: Autores Associados, HISTEDBR, 2002.

GOMES, R. M. Ofensiva do Capital e Transformações no Mundo Rural: a resistência camponesa e a luta pela terra no Triângulo Mineiro e Alto Paranaíba. 2004. Dissertação (Mestrado em Geografia)- Universidade Federal de Uberlândia, Uberlândia, 2004.

KUENZER, A. Z. Educação e trabalho no Brasil: o estado da questão. Brasília: INEP; Santiago: REDUC, 1987.

MARX, Karl. O Capital - Crítica da economia política. Trad. Reginaldo Sant’anna. $6^{\mathrm{a}}$ Edição. Rio de Janeiro: Civilização brasileira, 1980. Livro Primeiro. Vol.1

PONCE, A. Educação e luta de classes. Trad. José Severo de Camargo Pereira. $22^{a}$ edição. São Paulo: Cortez, 2007.

SAVIANI, D. O trabalho como princípio educativo frente às novas tecnologias. In: FERRETTI, C. J.; ZIBAS, D. M. L.; MADEIRA, F. R. \& FRANCO, M. L. P. B. (Orgs.). Novas tecnologias, trabalho e educação: um debate multidisciplinar. $8^{\mathrm{a} e d}$. Petrópolis: Vozes, 2002. 
Notas:

1 Mestre em Educação pela Faculdade de Educação da Universidade Federal de Uberlândia. E-mail: anacecilia1985@gmail.com

${ }^{2}$ Docente da Universidade Federal de Uberlândia - UFU. Programa de Pós-Graduação em Educação e Programa de Pós-Graduação em Ciências Sociais. Pesquisadora FAPEMIG/PPM. E-mail: fabianesp@netsite.com.br

${ }^{3}$ Segundo Marx (1980), Infra-estrutura são as relações materiais de produção, é a relação dialética do homem com a natureza através do trabalho e também as relações de produção estabelecidas entre os homens, esta por sua vez se relaciona com a Superestrutura, que representa a base ideológica de um determinado sistema de produção. São instituições como Estado, Religião, Escola, dentre outras.

Recebido em: $\quad$ 03/05/11

Aprovado em: $\quad 27 / 09 / 11$ 